\title{
Interactive comment on "On the Relationship between Teleconnections and Taiwan's Streamflow: Evidence of Climate Regime Shift and Implications for Seasonal Forecasting" by Chia-Jeng Chen and Tsung-Yu Lee
}

\section{Anonymous Referee \#2}

Received and published: 22 August 2016

\section{General comments}

The authors found significant correlation between Taiwan summer (July-September) catchment streamflow and the WP (West-Pacific) and PJ (Pacific-Japan) teleconnection indices, and demonstrated that the correlation relationship is not stable over a period of 50 years by calculating the correlation in a 20 -year running window. Significantly high correlation appears only during the years from 1979-1999. The authors further used Rodionov's method to identify the correlation change points and found two significant points at 1988 and 2000. These findings prompted the authors to discuss

Printer-friendly version

Discussion paper 
potential problems of using teleconnection indices as predictors for forecasting seasonal catchment streamflow. Although the subject is of great importance, the authors did not present sufficient scientific evidence to support the argument. I suggest the authors to continue the research and taking the following comments into account. The writing need to be more exact and concise.

Specific comments

1. P2L19-P2L26: I don't understand the point of this paragraph. "East Asia" is rather big compared with "Taiwan". Why is that "seeking the relationship between Taiwan's climate and large-scale circulations can provide some clue to direct the mechanisms of East Asian climate"? What are - the mechanisms of East Asian climate?

2. P3L14-P3L17: It seems to me that the authors wanted to use Taiwan as an example for "diagnosing underlying mechanisms of predictability and pointing caveats on intrinsic covariability between regional streamflow and large-scale circulation". However, the "predictability" and "caveats" depend strongly on the prediction model under discussion. Therefore, the "backbone" (P3L17) of the research should be a prediction model with acceptable prediction skill at least for a substantial period. In this regard, the following missing material is required to support the argument the authors trying to make.

(1) The authors need to present a prediction model that uses large-scale circulation to predict Taiwan streamflow with proved skill.

(2) The authors need to provide scientific evidence to explain the underlying mechanisms of the predictability of the prediction model.

(3) The authors need to show how variations of the intrinsic covariability influences the performance of the prediction model.

(4) With the evidence listed above, the authors can discuss the observed facts of climate regime shift and point out the caveats on using large-scale circulation indices to

Printer-friendly version

Discussion paper 
predict regional streamflow.

3. P3L28-P3L31: The two objectives listed here cannot be "objectives" because the scientific questions/purposes are not clear.

4. P4-P6: The "Data and Analysis Procedures" section should focus on discussing the "Data" and "Procedure", such as the data length (e.g. beginning and end years, ...), quality check (e.g. missing data issue and solution, ...), methodology (e.g. decision principles of the teleconnection / large-scale indices, ....). Other discussion such as the season (JAS) of study and references of teleconnection indices should be presented in the Introduction section.

5. P5L1-P5L14: The physical meaning of the teleconnection indices listed here is barely mentioned. It is not possible to diagnose "underlying mechanisms of predictability" without presenting the physical insight of the relationship between Taiwan climate and the large-scale circulation indices. Are all of the indices relevant to Taiwan climate variability?

6. The authors clearly showed that Taiwan JAS catchment streamflow is significantly correlated with the WP and PJ teleconnection indices and the correlation relationship changes with time. The large-scale climate also shows decadal-scale variations. However, time coincidence cannot be used for arguing physical relationship. For example, the argument of "The CRS firstly emanates from the change in the basin-scale climatology over the Pacific (e.g., shift in the PDO), and then the reorganized large-scale patterns can reset the relationship between the island-scale streamflow with established regional circulations (e.g., the PJ pattern)" on P9L12-14 is a hand-waving argument. Nothing is explained about how the decadal-scale changes of sea surfaces temperature (PDO) influences the regional circulation patter (PJ) in the atmosphere and then the rainfall pattern and subsequently the streamflow pattern in Taiwan.

There are many more hand-waving type of argument in the paper. There is no point to list out all of them here if the above points are not addressed. 
Interactive comment on Hydrol. Earth Syst. Sci. Discuss., doi:10.5194/hess-2016-216, 2016.

Interactive

comment 